31. Uuorisalo S, Haukipuro K, Pokela R, Sgrjala H. Risk features for surgical-site infections in coronary artery bypass surgery. Infect Control Hosp Epidemiol 1998;19:240-247.

32. Kahn M, Steib S, Fraser V, Dunagan W. Expert system for culture-based infection control surveillance. Proceedings: The Annual Symposium on Computer Applications in Medical Care. 1993;171-75.

33. Garner IS, Jarvis WR, Emori TG, Horan TC, Hughes JM. CDC definitions for nosocomial infections, 1988. Am J Infect Control 1988;16:128-140.

34. Armitage P, Berry G. Statistical Methods in Medical Research. 3rd ed. Oxford, England: Blackwell Science; 1994.

35. Kleinbaum DG, Kupper LL, Morgenstern H. Epidemiologic Research. Belmont, CA: Lifetime Learning Publishers; 1982.

36. Higgins TL, Estafanous FG, Loop FD, Beck GJ, Blum JM, Paranandi L. Stratification of morbidity and mortality outcome by preoperative risk factors in coronary artery bypass patients. JAMA 1992;267:2344-2348.

37. Hosmer DW, Lemeshow S. Applied Logistic Regression. New York, NY: Wiley; 1989.
38. American Society of Health-System Pharmacists Commission on Therapeutics. ASHP therapeutic guidelines on antimicrobial prophylaxis in surgery. Clin Pharm 1992;11:483-513.

39. Page CP, Bohnen JM, Fletcher R, McManus AT, Solomkin JS, Wittmann $\mathrm{DH}$. Antimicrobial prophylaxis for surgical wounds: guidelines for clinical care. Arch Surg 1993;128:79-88.

40. Dellinger EP, Gross PA, Barrett TL, Krause PJ, Mortone WJ, McGowan JE Jr, et al. Quality standard for antimicrobial prophylaxis in surgical procedures. Clin Infect Dis 1994;18:422-427.

41. Antimicrobial prophylaxis in surgery. The Medical Letter 1995;37:79-82.

42. Nichols RL. Update: antibiotic prophylaxis in surgery. Infect Dis Clin Pract 1996;5(suppl 2):S77-S84.

43. O'Conner GT, Plume SK, Olmstead EM, Morton JR, Maloney CT, Nugent WC, et al. A regional intervention to improve the hospital mortality associated with coronary artery bypass graft surgery. JAMA $1996 ; 275: 841-846$.

\title{
Using NNIS Data to Reduce UTIs
}

\section{Gina Pugliese, RN, MS Martin S. Favero, $\mathrm{PhD}$} Hospital of Saint Raphael, New Haven, Connecticut, reported on a study whose aim was to reduce catheterrelated urinary tract infection (UTI) rates in three ICUs to at or below the National Nosocomial Infection Surveillance System pooled mean for similar units. A nursing team, physician team, and laboratory team reviewed and revised protocols and procedures for better catheter management in a 500 bed community teaching hospital. The
Dumigan and coworkers from the

teams developed medical indications for urinary catheter placement and criteria that allowed the registered nurse to remove a catheter without a physician's order when no longer medically necessary. They created a computer prompt to assure a urinalysis accompanied all urine cultures.

After introducing the new protocols, the incidence density of catheter-related UTIs fell $17 \%$ in the surgical ICU, $29 \%$ in the medical intensive-care acute unit, and $45 \%$ in the coronary intensive-care acute unit. The registered nurses' compliance in removing the catheter per protocol was $88 \%$. Physician ordering

\section{VRE in ICUs}

Austin and coinvestigators from the University of Oxford, United Kingdom, and Cook County Hospital in Chicago, Illinois, have described the transmission of nosocomial pathogens by using a micro-epidemiological framework based on the transmission dynamics of vector-borne diseases. By using the concept of a basic reproductive number, R0, defined as the average number of secondary cases generated by one primary case, they show quantitatively how infection control measures such as hand washing, cohorting, and antibiotic restriction affect nosocomial cross-transmission. By using detailed molecular epidemiological surveillance and compliance monitoring, they found that the estimated basic reproductive number for vancomycin-resistant enterococci (VRE) during a study at Cook County Hospital was approximately 3 to 4 without infection control and 0.7 when infection control measures were included. The impact of infection control was to reduce the prevalence from a predicted $79 \%$ to an observed $36 \%$. Hand washing and staff cohorting were the most powerful control measures, although their efficacy depended on the magnitude of R0. Under the circumstances tested, endemicity of VRE was stabilized, despite infection control measures, by the constant introduction of colonized patients. Multiple stochastic simulations of the model revealed excellent agreement with observed patterns. In of a concomitant urinalysis with each urine culture achieved $93 \%$. The authors concluded that a multidisciplinary approach assisted in reducing catheter-associated UTIs in three ICUs, although not to the extent desired. The teams are investigating preconnected and antimicrobialcoated catheters further.

FROM: Dumigan DG, Kohan CA, Reed CR, Jekel JF, Fikrig MK. Utilizing National Nosocomial Infection Surveillance System data to improve urinary tract infection rates in three intensivecare units. Clinical Performance and Quality Health Care 1998;6:172-178. conjunction with detailed microbiological surveillance, a mathematical framework provides a precise template to describe the colonization dynamics of VRE in ICUs and impact of infection control measures. The analyses suggest that compliance for hand washing significantly in excess of reported levels or the cohorting of nursing staff are needed to prevent nosocomial transmission of VRE in endemic settings.

FROM: Austin DJ, Bonten MJ, Weinstein RA, Slaughter S, Anderson RM. Vancomycin-resistant enterococci in intensive-care hospital settings: transmission dynamics, persistence, and the impact of infection control programs. Proc Natl Acad Sci USA 1999;96:6908-6913. 